\title{
Low Self-Confidence and Diabetes Mismanagement in Youth with Type 1 Diabetes Mediate the Relationship between Behavioral Problems and Elevated HbA1c
}

\author{
Minke M. A. Eilander, ${ }^{1,2}$ Maartje de Wit, ${ }^{1,2}$ Joost Rotteveel, ${ }^{2,3}$ and Frank J. Snoek ${ }^{1,2,4}$ \\ ${ }^{1}$ Department of Medical Psychology, VU University Medical Center, De Boelelaan 1117, 1081 HV Amsterdam, Netherlands \\ ${ }^{2} E M G O+$ Institute for Health and Care Research, VU University Medical Center, Van der Boechorststraat 7, \\ 1081 BT Amsterdam, Netherlands \\ ${ }^{3}$ Department of Pediatrics, VU Medical Center, De Boelelaan 1118, 1081 HV Amsterdam, Netherlands \\ ${ }^{4}$ Department of Medical Psychology, Academic Medical Center (AMC), Meibergdreef 9, 1100 DD Amsterdam, Netherlands
}

Correspondence should be addressed to Minke M. A. Eilander; m.eilander@vumc.nl

Received 10 December 2014; Revised 6 May 2015; Accepted 7 May 2015

Academic Editor: S. K. Mattoo

Copyright (c) 2016 Minke M. A. Eilander et al. This is an open access article distributed under the Creative Commons Attribution License, which permits unrestricted use, distribution, and reproduction in any medium, provided the original work is properly cited.

\begin{abstract}
Introduction. Previous studies indicated an association between behavior problems (internalizing, externalizing) and glycemic control (HbAlc) in youth with type 1 diabetes (T1D). The aim of this study is to examine if this association is mediated by self-confidence and mismanagement of diabetes. Methods. Problem behavior was assessed with the Strengths and Difficulties Questionnaire. Mediating variables were assessed using the Confidence in Diabetes Self-Care-Youth and Diabetes Mismanagement Questionnaire. HbAlc was derived from hospital charts. Bootstrap mediation analysis for multiple mediation was utilized. Results. 88 youths with T1D, age 11-15y, participated. The relation between both overall problem behavior and externalizing behavior problems and $\mathrm{HbAlc}$ was mediated through confidence in diabetes self-care and mismanagement $\left(a_{1} b_{1}+a_{2} b_{2}\right.$ path; point estimate $=$ $0.50 \mathrm{BCa}$ CI 95\% 0.25-0.85; $a_{1} b_{1}+a_{2} b_{2}$ path; point estimate $=0.73 \mathrm{BCa}$ CI 95\% 0.36-1.25). Conclusions. Increased problem behavior in youth with T1D is associated with elevated HbAlc and mediated by low self-confidence and diabetes mismanagement. Screening for problem behavior and mismanagement and assisting young patients in building confidence seem indicated to optimize glycemic control.
\end{abstract}

\section{Introduction}

Adolescence is characterized by major biological and psychosocial changes, which interact in complex ways. This is particularly true for youth with type 1 diabetes (T1D) and probably explains the fact that youth with diabetes have the poorest glycemic control of all age groups, with less than $15 \%$ of adolescents with type T1D reaching Hemoglobin Alc (HbAlc) levels below target [1-5]. On top of the hormonal changes that negatively affect blood glucose control, adolescents with T1D have an increased risk of developing depression, anxiety, and disturbed eating behaviors, relative to healthy youth. These problems typically occur in midadolescence [6] and result in poor glycemic control [711]. Externalizing behavior problems (e.g., attention and disruptive behavior complaints) are associated with decreased glycemic control as well [12-15]. Although behavior problems at diagnosis do not seem to impact lifelong poor glycemic control [16], they have been found to be directly associated with hyperglycemia [15]. Adolescents showing external problem behavior seem to be generally unresponsive to punishment, are often impulsive, and have concentration problems [17]. Problematic behavior, both internal and external, frequently coincides with low self-efficacy beliefs, low selfesteem, dysfunctional coping mechanisms, and increased risk taking behavior, all complicating daily self-management of diabetes [17]. Self-efficacy beliefs, for example, low selfconfidence, and diabetes mismanagement are likely to mediate the relationship between behavior problems and poor glycemic outcomes, but this hypothesis has not been previously tested. 
Using baseline data of multicenter cohort DINO study (diabetes in development) that examines the complex interaction between biological and psychosocial development during adolescence [18], we examined whether overall, external, and internal problem behavior are associated with glycemic control and whether this relationship is mediated by confidence in diabetes self-care and mismanagement.

\section{Materials and Methods}

2.1. Participants. Youth aged 8 to 15 treated $(N=598)$ in 5 pediatric diabetes centers in Netherlands were invited to participate in the DINO study. The participating centers provide secondary and tertiary clinical care to children and adolescents with T1D in their region and can be considered representative of youth with T1D in Netherlands. Exclusion criteria were mental retardation, diabetes other than type 1 , and diagnosis less than 6 months prior to the start of the study. Written informed consent was obtained from all parents and adolescents 12 years and older. Participants completed an online survey. In view of their age, 8-11-yearolds completed a shorter survey than participants 11 years and older. Data from the latter survey were used for the study reported in this paper. In total, 151 children and adolescents (25.3\%) agreed to participate, of whom 100 were $\geq 11$ years.

The DINO study was approved by the Medical Ethical Committee of VU University Medical Center.

2.2. Measures. Problem behavior was assessed using the Strengths and Difficulties Questionnaire (SDQ). SDQ [19, 20] captures emotional and behavioral functioning and contains 25 items, rated on a 3-point Likert scale (e.g., "Other people my age generally like me"). The SDQ comprises five scales: emotional symptoms, conduct problems, hyperactivity/inattention, peer relationship problems, and prosocial behavior. The overall score of problem behavior (range 040) can be divided into external (range 0-20) and internal (range $0-20$ ) problem behavior. Cronbach's $\alpha$ was 0.70 on the overall scale $[19,20]$, in the current study 0.60 . Higher scores indicate more problematic behavior; scores $\leq 13$ are considered normal.

Confidence in diabetes self-care was assessed using an adapted adolescent version of the Confidence in Diabetes Self-Care Scale (CIDS) [21]. The original adult version of the CIDS consists of 20 items on a 5-point Likert scale, Cronbach's $\alpha=0.86$ [21]. The adapted youth version consists of 12 items (e.g., "I believe I can check my blood glucose at least 2 times a day"): 10 of the original questionnaire, 2 items combined to 1 (original questions 2 and 20), and 1 additional item regarding alternations in blood glucose. Cronbach's $\alpha$ of the CIDS-Youth in the current study was 0.79 . Higher scores represent higher diabetes self-confidence (range 12-60).

Mismanagement in diabetes self-care was assessed using an adapted version of the mismanagement scale [22]. The original version consists of 10 items of which 3 items were used and 1 was adjusted. The recall period was changed from 10 days to the past week. Answers are given on a 5-point Likert scale (e.g., "In the past 7 days, how often did you miss
TABLE 1: Characteristics of participating adolescents.

\begin{tabular}{lc}
\hline Boys (N/\%) & $45(51.1)$ \\
Age (yrs) & $12.9 \pm 1.2$ \\
HbAlc & $64.3 \mathrm{mmol} / \mathrm{mol}(8.0 \%) \pm$ \\
& $11.5 \mathrm{mmol} / \mathrm{mol}$ \\
Age diabetes onset & $7.1 \pm 3.8$ \\
Diabetes duration (yrs) & $5.8 \pm 3.8$ \\
Pump/injections (\%) & $80.7 / 19.3 \geq 4$ per day \\
Traditional family composition (\%) & 83 \\
SDQ overall problem behavior & $8.6 \pm 4.3$ \\
(0-40) & $4.9 \pm 2.8$ \\
SDQ external problem behavior & $3.7 \pm 2.8$ \\
$(0-20)$ & $51.2 \pm 5.3$ \\
SDQ internal problem behavior & $6.4 \pm 2.0$ \\
(0-20) & \\
CIDS-Youth (12-60) & \\
Mismanagement (4-16) &
\end{tabular}

Data are means \pm SD, unless otherwise indicated.

shots/did not bolus?"). Cronbach's $\alpha$ of the original version is 0.74 and 0.60 , respectively [22]. Cronbach's $\alpha$ of the adapted version in the current study was 0.47 . Higher scores indicate more mismanagement (range 4-16).

Demographic and diabetes related data were derived from hospital charts during the same period as the completion of the survey. HbAlc was used as a marker of glycemic control over the past $8-12$ weeks, with recommended target $<7.5 \%$, $58 \mathrm{mmol} / \mathrm{mol}[23]$.

2.3. Analyses. $t$-tests and chi-square tests were applied in order to examine differences in $\mathrm{HbAlc}$, age, and gender between responding and nonresponding adolescents. To examine whether there was a relationship between problem behavior (overall, external, and internal) and glycemic control and whether this relationship is mediated by confidence in diabetes self-care and diabetes mismanagement, bootstrap mediation analysis for multiple mediation through the Indirect Macro was applied [24, 25], correcting for age and gender. Since we chose to use more than one possible mediator, this method was considered more appropriate than traditional models [24, 26-28]. Analyses were performed with a bootstrap of 5000 resamples, in which random samples based on the original data are generated. A 95\% confidence interval (CI) was calculated [25].

\section{Results}

A total of 88 adolescents (45 boys) completed the online survey $(88.0 \%$ of the 100 youths $\geq 11 \mathrm{y})$, mean age 12.9 $( \pm 1.2)$ years with a mean disease duration of almost 6 years. Baseline characteristics are shown in Table 1. There were no differences in $\mathrm{HbAlc}$, age, and gender between responders and nonresponders. Thirteen adolescents (14.8\%) reported problem behavior above the normal range (overall problem 


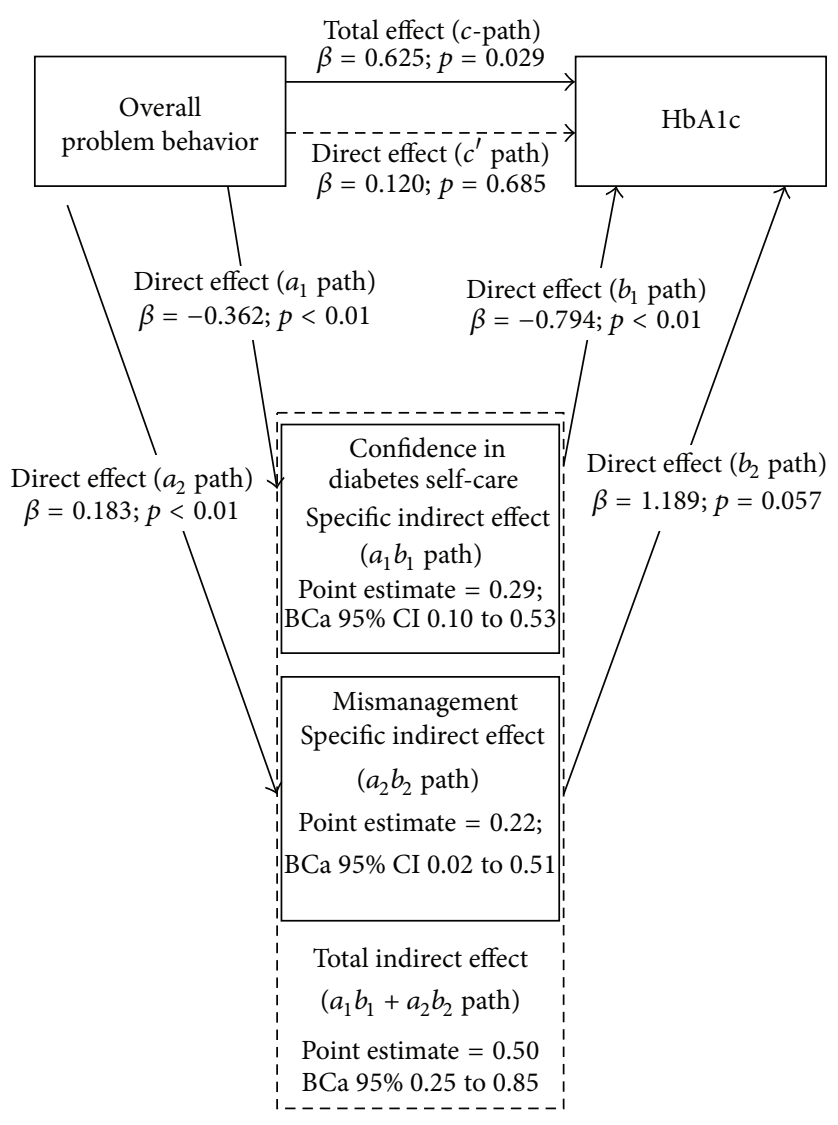

FIGURE 1: Graphic representation of the multiple mediation model of the associations between overall problem behavior and glycemic control with confidence in diabetes self-care and mismanagement of diabetes self-care. 5000 resamples were calculated while using the bootstrap method [24].

behavior score > 13). Almost three-quarters of adolescents (72.7\%) had HbAlc levels above target.

3.1. Overall Problem Behavior. Figure 1 shows the multiple mediation model of the associations between overall problem behavior and glycemic control. A significant total effect (cpath) was found between overall problem behavior and glycemic control $(\beta=0.625, p=0.029)$, indicating that higher overall problem behavior scores are associated with higher HbAlc. Mediation analysis showed that this relationship was mediated by confidence in diabetes self-care and mismanagement as the indirect effect was significant $\left(a_{1} b_{1}+a_{2} b_{2}\right.$ path point estimate $=0.50$, BCa $95 \% 0.25$ to $0.85)$ and the direct effect ( $c^{\prime}$ path) was not anymore $(\beta=$ $0.120, p=0.685)$. Increased overall problem behavior was associated with higher confidence in diabetes self-care $\left(a_{1}\right.$ path $\beta=-0.362, p<0.01)$ and worse self-care of diabetes ( $a_{2}$ path $\beta=0.183, p<0.01$ ). Lower confidence in diabetes self-care was associated with higher $\operatorname{HbAlc}\left(b_{1}\right.$ path $\beta=$ $-0.794, p<0.01)$. The association between mismanagement of diabetes and higher HbAlc was borderline significant $\left(b_{2}\right.$ path $\beta=1.189, p=0.057)$.

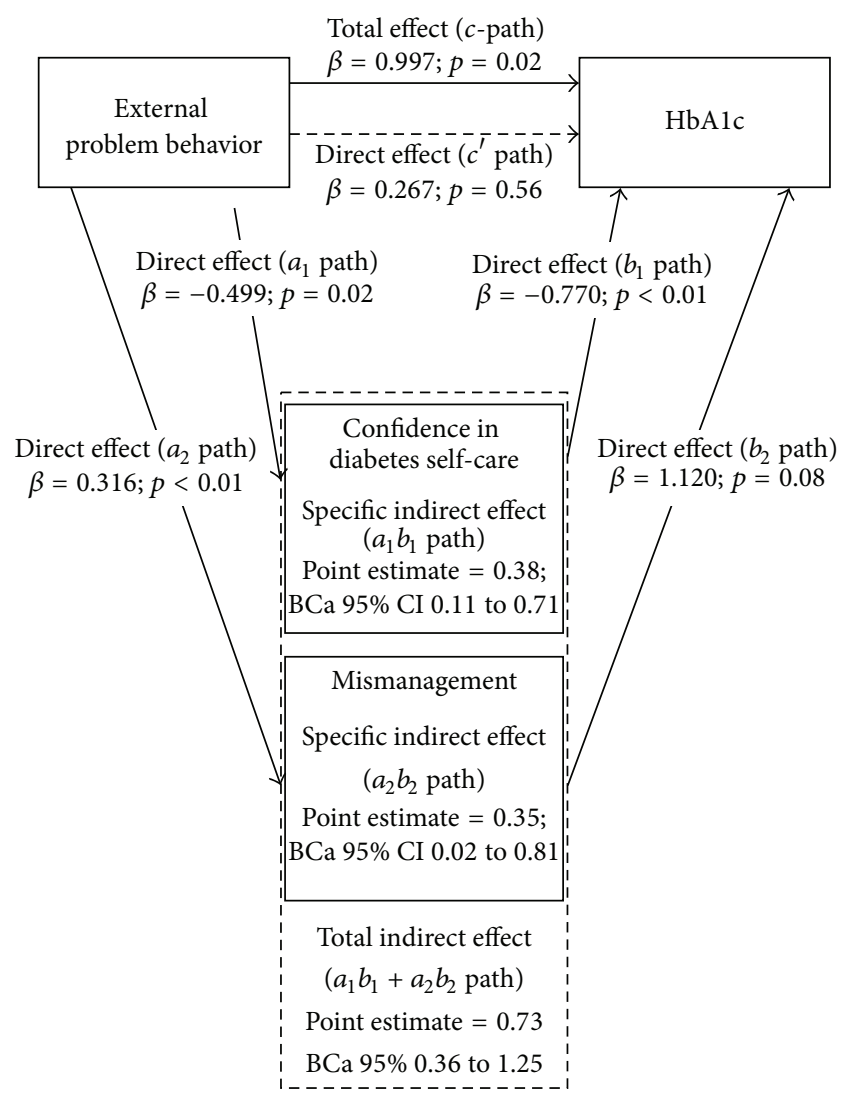

FIGURE 2: Graphic representation of the multiple mediation model of the associations between external problem behavior and glycemic control. 5000 resamples were calculated while using the bootstrap method [24].

3.2. External Problem Behavior. Figure 2 shows the multiple mediation model of the associations between external problem behavior and glycemic control. A significant total effect (c-path) was found between external problem behavior and glycemic control $(\beta=1.00, p=0.02)$ : increased external problem behavior was associated with higher HbAlc. Again, multiple mediation analysis showed that this relationship was mediated by confidence in diabetes self-care and mismanagement as the indirect effect $\left(a_{1} b_{1}+a_{2} b_{2}\right.$ path point estimate $=0.73, \mathrm{BCa} 95 \% 0.36$ to 1.25$)$ was significant and the direct effect $\left(c^{\prime}\right.$ path $\left.\beta=0.27, p=0.56\right)$ was not anymore. Increased external problem behavior was associated with low confidence in diabetes self-care $\left(a_{1}\right.$ path $\left.\beta=-0.49, p=0.02\right)$ and worse self-management of diabetes $\left(a_{2}\right.$ path $\beta=0.32, p<$ $0.01)$. Low confidence in diabetes self-care and worse selfmanagement of diabetes were both associated with higher HbAlc; however the latter was not significant $\left(b_{1}\right.$ path $\beta=$ $-0.77, p<0.01 ; b_{2}$ path $\left.\beta=1.12, p=0.08\right)$.

3.3. Internal Problem Behavior. Figure 3 shows the multiple mediation model of the associations between internal problem behavior and glycemic control. In contrast to the overall and external problem behavior, the total effect between internal problem behavior and glycemic control was not 


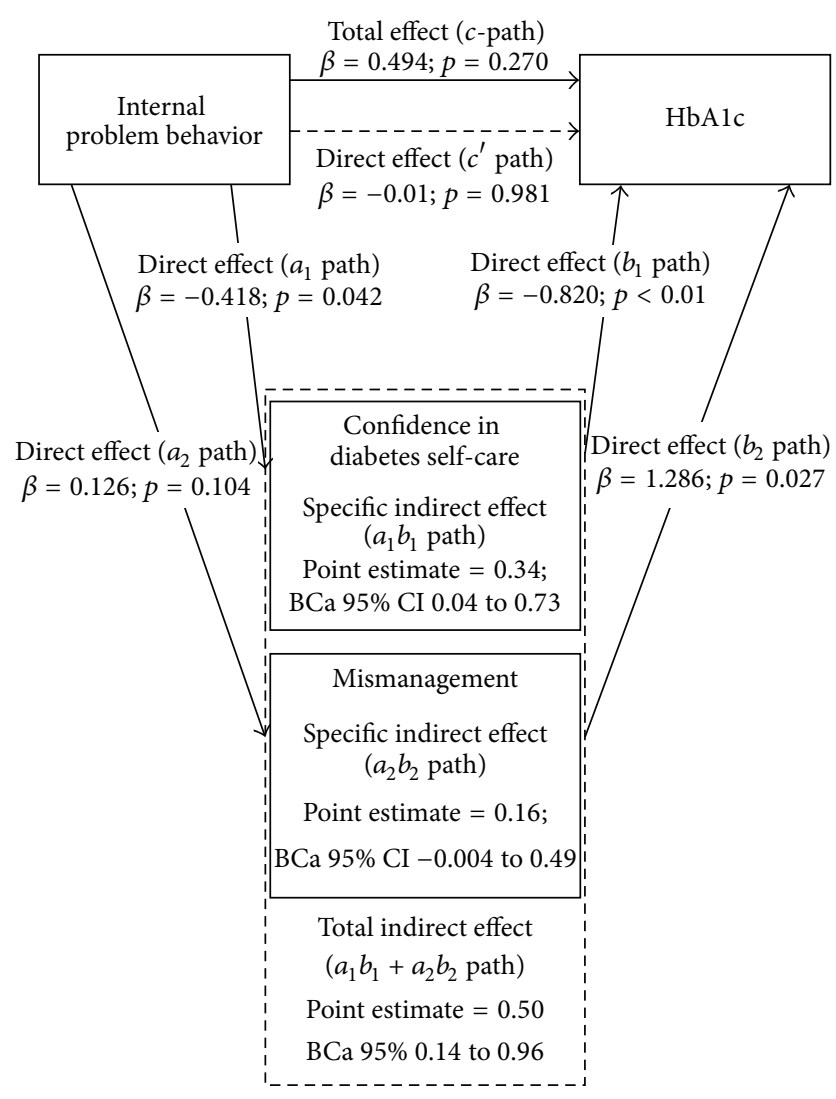

FIGURE 3: Graphic representation of the multiple mediation model of the associations between internal problem behavior and glycemic control. 5000 resamples were calculated while using the bootstrap method [24].

significant ( $c$-path $\beta=0.494, p=0.270$ ). However, multiple mediation analysis did show a significant mediation by confidence in diabetes self-care and mismanagement as the indirect effect was significant $\left(a_{1} b_{1}+a_{2} b_{2}\right.$ path point estimate $=0.50$, BCa $95 \% 0.14$ to 0.96 ). The association of the direct effect ( $c^{\prime}$ path $\beta=-0.01, p=0.981$ ) decreased as a result of this mediation. Increased internal problem behavior was associated with low confidence in diabetes self-care $\left(a_{1}\right.$ path $\beta=-0.418, p=0.042)$, but not with worse selfmanagement of diabetes ( $a_{2}$ path $\beta=0.126, p=0.104$ ). Low confidence in diabetes self-care and worse self-management were both associated with a higher HbAlc $\left(b_{1}\right.$ path $\beta=$ $-0.820, p<0.01 ; b_{2}$ path $\left.\beta=1.286, p=0.027\right)$.

\section{Discussion}

The aim of the present study in adolescents with T1D was to investigate whether there is a relationship between problem behavior and glycemic control and whether this relationship is mediated by low confidence in diabetes self-care and mismanagement of diabetes. Increased overall and external problem behavior were found to be associated with increased $\mathrm{HbAlc}$ and these relationships were mediated by confidence in diabetes self-care and self-management of diabetes. Interestingly no total effect was found between internal problem behavior and glycemic control, and the relationship between internal problem behavior and diabetes management was not significant; however, the indirect effect was significant. We should interpret these findings with caution, as the relationship could be dose-dependent: the risk of worsened illness management increases when internal problems get more serious [17]. The adolescents participating in our study reported somewhat less problematic behavior on all three SDQ scales (overall, external, and internal problem behavior) compared to the 11-16-year-old adolescents participating in SDQ validation study published in 2003 (overall $M=8.6$ compared to 9.9, external $M=4.9$ compared to 5.8, and internal $M=3.7$ compared to 4.1) [19]. Our sample appears less problematic than previously reported in the literature where adolescents with T1D were found to have more problem behavior compared to healthy peers [7-10]. Possible explanations for this discrepancy could be that we included a slightly younger group compared to the SDQ validation study, a selection bias, or the fact that previous research was conducted a decade ago. Nevertheless, almost $15 \%$ of the adolescents in our study reported levels of problem behavior above the normal range. This underscores the clinical relevance of our proposed model.

The relationship between more behavior problems and suboptimal HbAlc levels has been demonstrated in other studies as well [12-14]. The present study confirms our hypothesis that this relationship is mediated by confidence and self-management of diabetes. More behavioral problems seem to decrease the adolescent's confidence in the management of their diabetes, in concordance with previous research [17]. The need to address psychosocial issues in pediatric diabetes care is recognized [29, 30]. Psychosocial well-being is an important outcome in and of itself but also has clear relevance to understanding problems in achieving satisfactory glycemic control [31,32]. Timely detection and management of psychosocial issues, however, have been shown to be difficult in routine care, where time is limited and measurements of adolescents' physical health often have priority [33]. Our findings corroborate the clinical relevance of finding practical ways to ensure that assessment and management of behavioral problems in adolescents are in place.

4.1. Limitations. Although the current study contributes to enhancing our understanding of the complex interactions between psychosocial and biological developmental trajectories, some limitations should be taken into account. First, our study was cross-sectional and we cannot infer causality. The 12-year study of Northam et al. examined the relationship between problem behavior at diagnosis and longtime poor glycemic control but did not look at possible mediating pathways [16]. Future longitudinal research is planned to examine this relationship in more detail. Moreover, the relationship between the psychosocial development and diabetes outcomes is multifaceted. In the present study we only tested the contribution of a few of the factors involved and took 
HbAlc as a marker for glycemic control. In addition, we may want to explore the momentary impact of behavior problems on blood glucose fluctuations which is likely to exist. Conversely, high and low blood glucose values can influence the adolescents' behavior, thereby creating a vicious cycle of events [34]. With regard to the measurements, we chose to administer the questionnaires via the internet, for pragmatic reasons. Also online administration of questionnaires is patient-friendly and more appealing to adolescents than traditional paper-and-pencil. We should acknowledge that we cannot validate that respondents have all filled in the online questionnaire without interference from others (e.g., parent, siblings); however, several studies have shown over the years that questionnaires completed via the internet are as reliable as paper-and-pencil $[35,36]$. The internal consistency (Cronbach's $\alpha$ ) of the adapted version of the mismanagement scale proved to be relatively low in our study $(\alpha=0.47)$. This may be due to the fact that management behaviors are relatively independent of one another or due to the small number of items, as the adapted version of the questionnaire consists of 4 rather than the 10 items in the original questionnaire. Psychometric validation of the scale warrants further research.

\section{Conclusion}

More problem behavior in adolescents with type 1 diabetes is associated with worsened glycemic control and this relationship is mediated by low confidence in diabetes self-care and poorer self-management of the diabetes. This finding has clinical implications. Psychosocial screening should include both internal problem behavior and external problem behavior. To assist adolescents in achieving better glycemic control, it would seem imperative to help them build their confidence and reduce diabetes mismanagement, for example, improving their self-care practices.

\section{Conflict of Interests}

The authors declare that there is no conflict of interests regarding the publication of this paper.

\section{Authors' Contribution}

Minke M. A. Eilander conducted the design of the study, collected and researched data, and wrote the paper. Maartje de Wit conducted the design of the study and reviewed and edited the paper. Joost Rotteveel reviewed and edited the paper. Frank J. Snoek reviewed and edited the paper.

\section{Acknowledgments}

This study was supported by the Dutch Diabetes Foundation, Grant 2011.13.1449. The authors acknowledge the diabetes care teams from Diabeter, Rotterdam, Netherlands; Juliana Children's Hospital/Haga Hospital, The Hague, Netherlands; Meander Medical Center, Amersfoort, Netherlands; University Hospital of Groningen, Netherlands; VU University Medical Center, Amsterdam, Netherlands.

\section{References}

[1] P. Dabadghao, S. Vidmar, and F. J. Cameron, "Deteriorating diabetic control through adolescence-do the origins lie in childhood?" Diabetic Medicine, vol. 18, no. 11, pp. 889-894, 2001.

[2] K. Luyckx and I. Seiffge-Krenke, "Continuity and change in glycemic control trajectories from adolescence to emerging adulthood: relationships with family climate and self-concept in type 1 diabetes," Diabetes Care, vol. 32, no. 5, pp. 797-801, 2009.

[3] K. S. Bryden, R. C. Peveler, A. Stein, A. Neil, R. A. Mayou, and D. B. Dunger, "Clinical and psychological course of diabetes from adolescence to young adulthood: a longitudinal cohort study," Diabetes Care, vol. 24, no. 9, pp. 1536-1540, 2001.

[4] V. S. Helgeson, K. A. Reynolds, L. Siminerio, O. Escobar, and D. Becker, "Parent and adolescent distribution of responsibility for diabetes self-care: links to health outcomes," Journal of Pediatric Psychology, vol. 33, no. 5, pp. 497-508, 2008.

[5] B. J. Anderson, J. Brackett, J. Ho, and L. M. B. Laffel, "An officebased intervention to maintain parent-adolescent teamwork in diabetes management: impact on parent involvement, family conflict, and subsequent glycemic control," Diabetes Care, vol. 22, no. 5, pp. 713-721, 1999.

[6] G. N. Holmbeck, M. Abad, D. Friedman, and B. Jandasek, "Development and psychopathology in adolescents," in Behavioral and Emotional Disorders in Adolescents: Nature, Assessment, and Treatment, D. A. Wolfe and E. J. Mash, Eds., pp. 21-55, Guilford Press, New York, NY, USA, 2006.

[7] C. Dantzer, J. Swendsen, S. Maurice-Tison, and R. Salamon, "Anxiety and depression in juvenile diabetes: a critical review," Clinical Psychology Review, vol. 23, no. 6, pp. 787-800, 2003.

[8] B. J. Blanz, B. S. Rensch-Riemann, D. I. Fritz-Sigmund, and M. H. Schmidt, "IDDM is a risk factor for adolescent psychiatric disorders," Diabetes Care, vol. 16, no. 12, pp. 1579-1587, 1993.

[9] J. M. Lawrence, D. A. Standiford, B. Loots et al., "Prevalence and correlates of depressed mood among youth with diabetes: the SEARCH for diabetes in youth study," Pediatrics, vol. 117, no. 4, pp. 1348-1358, 2006.

[10] K. Hassan, R. Loar, B. J. Anderson, and R. A. Heptulla, "The role of socioeconomic status, depression, quality of life, and glycemic control in type 1 diabetes mellitus," Journal of Pediatrics, vol. 149, no. 4, pp. 526-531, 2006.

[11] E. A. Northam, L. K. Matthews, P. J. Anderson, F. J. Cameron, and G. A. Werther, "Psychiatric morbidity and health outcome in type 1 diabetes-Perspectives from a prospective longitudinal study," Diabetic Medicine, vol. 22, no. 2, pp. 152-157, 2005.

[12] D. C. Duke, G. R. Geffken, A. B. Lewin, L. B. Williams, E. A. Storch, and J. H. Silverstein, "Glycemic control in youth with type 1 diabetes: family predictors and mediators," Journal of Pediatric Psychology, vol. 33, no. 7, pp. 719-727, 2008.

[13] D. M. Cohen, M. A. Lumley, S. Naar-King, T. Partridge, and N. Cakan, "Child behavior problems and family functioning as predictors of adherence and glycemic control in economically disadvantaged children with type 1 diabetes: a prospective study," Journal of Pediatric Psychology, vol. 29, no. 3, pp. 171-184, 2004.

[14] M. Kovacs, D. Charron-Prochownik, and D. S. Obrosky, "A longitudinal study of biomedical and psychosocial predictors of multiple hospitalizations among young people with insulindependent diabetes mellitus," Diabetic Medicine, vol. 12, no. 2, pp. 142-148, 1995.

[15] C. M. McDonnell, E. A. Northam, S. M. Donath, G. A. Werther, and F. J. Cameron, "Hyperglycemia and externalizing behavior 
in children with type 1 diabetes," Diabetes Care, vol. 30, no. 9, pp. 2211-2215, 2007.

[16] E. A. Northam, A. Lin, S. Finch, G. A. Werther, and F. J. Cameron, "Psychosocial well-being and functional outcomes in youth with type 1 diabetes 12 years after disease onset," Diabetes Care, vol. 33, no. 7, pp. 1430-1437, 2010.

[17] A. Carr, The Handbook of Child and Adolescent Clinical Psychology. A Contextual Approach, Routledge, London, UK, 2006.

[18] M. M. A. Eilander, M. de Wit, J. Rotteveel et al., "Diabetes IN development (DINO): the bio-psychosocial, family functioning and parental well-being of youth with T1D: a longitudinal cohort study design," submitted to BMJ Paediatrics.

[19] B. M. van Widenfelt, A. W. Goedhart, P. D. A. Treffers, and R. Goodman, "Dutch version of the Strengths and Difficulties Questionnaire (SDQ)," European Child and Adolescent Psychiatry, vol. 12, no. 6, pp. 281-289, 2003.

[20] R. Goodman, "The strengths and difficulties questionnaire: a research note," Journal of Child Psychology and Psychiatry, vol. 38, no. 5, pp. 581-586, 1997.

[21] N. C. W. Van Der Ven, K. Weinger, J. Yi et al., "The confidence in diabetes self-care scale: psychometric properties of a new measure of diabetes-specific self-efficacy in Dutch and U.S. patients with type 1 diabetes," Diabetes Care, vol. 26, no. 3, pp. 713-718, 2003.

[22] J. Weissberg-Benchell, A. M. Glasgow, W. D. Tynan, P. Wirtz, J. Turek, and J. Ward, "Adolescent diabetes management and mismanagement," Diabetes Care, vol. 18, no. 1, pp. 77-82, 1995.

[23] M. J. Rewers, K. Pillay, C. de Beaufort et al., "Assessment and monitoring of glycemic control in children and adolescents with diabetes," Pediatric Diabetes, vol. 15, supplement 20, pp. 102-114, 2014.

[24] K. J. Preacher and A. F. Hayes, "Asymptotic and resampling strategies for assessing and comparing indirect effects in multiple mediator models," Behavior Research Methods, vol. 40, no. 3, pp. 879-891, 2008.

[25] A. F. Hayes, Introduction to Mediation, Moderation, and Conditional Process Analysis, Guilford Press, New York, NY, USA, 2013.

[26] R. M. Baron and D. A. Kenny, “The moderator-mediator variable distinction in social psychological research: conceptual, strategic, and statistical considerations," Journal of Personality and Social Psychology, vol. 51, no. 6, pp. 1173-1182, 1986.

[27] A. F. Hayes, "Beyond Baron and Kenny: statistical mediation analysis in the new millennium," Communication Monographs, vol. 76, no. 4, pp. 408-420, 2009.

[28] P. E. Shrout and N. Bolger, "Mediation in experimental and nonexperimental studies: new procedures and recommendations," Psychological Methods, vol. 7, no. 4, pp. 422-445, 2002.

[29] M. de Wit, H. A. D.-V. de Waal, J. A. Bokma et al., "Monitoring and discussing health-related quality of life in adolescents with type 1 diabetes improve psychosocial well-being: a randomized controlled trial," Diabetes Care, vol. 31, no. 8, pp. 1521-1526, 2008.

[30] A. Jones, M. Vallis, and F. Pouwer, "If it does not significantly change $\mathrm{HbA}_{1 c}$ levels why should we waste time on it? A plea for the prioritization of psychological well-being in people with diabetes ," Diabetic Medicine, vol. 32, no. 2, pp. 155-163, 2015.

[31] F. J. Cameron, D. Smidts, K. Hesketh, M. Wake, and E. A. Northamt, "Early detection of emotional and behavioural problems in children with diabetes: the validity of the Child Health Questionnaire as a screening instrument," Diabetic Medicine, vol. 20 , no. 8, pp. 646-650, 2003.
[32] M. Wake, K. Hesketh, and F. Cameron, "The Child Health Questionnaire in children with diabetes: cross-sectional survey of parent and adolescent-reported functional health status," Diabetic Medicine, vol. 17, no. 10, pp. 700-707, 2000.

[33] M. Eilander, M. de Wit, J. Rotteveel, N. Maas-van Schaaijk, A. Roeleveld-Versteegh, and F. Snoek, "Implementation of quality of life monitoring in Dutch routine care of adolescents with type 1 diabetes: appreciated but difficult," Pediatric Diabetes, 2015.

[34] L. A. Gonder-Frederick, D. J. Cox, S. A. Bobbitt, and J. W. Pennebaker, "Mood changes associated with blood glucose fluctuations in insulin-dependent diabetes mellitus," Health Psychology, vol. 8, no. 1, pp. 45-59, 1989.

[35] N. L. Young, J. W. Varni, L. Snider et al., "The Internet is valid and reliable for child-report: an example using the Activities Scale for Kids (ASK) and the Pediatric Quality of Life Inventory (PedsQL)," Journal of Clinical Epidemiology, vol. 62, no. 3, pp. 314-320, 2009.

[36] J. W. Varni, C. A. Limbers, T. M. Burwinkle, W. P. Bryant, and D. P. Wilson, "The ePedsQL in type 1 and type 2 diabetes feasibility, reliability, and validity of the pediatric quality of life inventory internet administration," Diabetes Care, vol. 31, no. 4, pp. 672$677,2008$. 


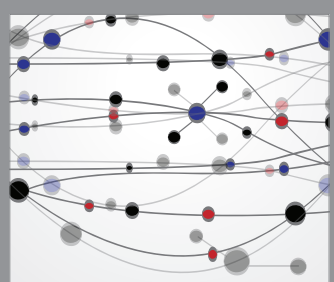

The Scientific World Journal
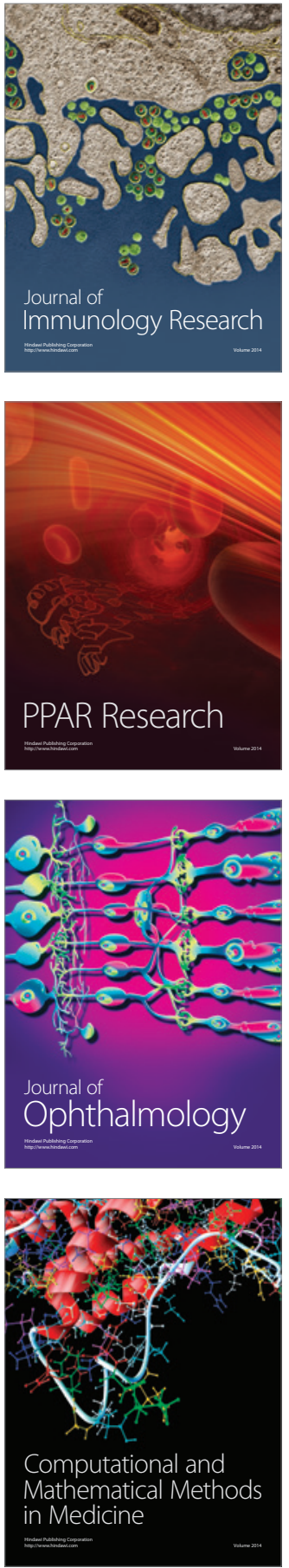

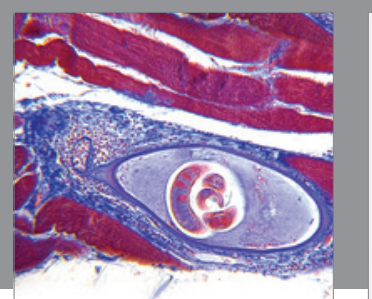

Gastroenterology Research and Practice

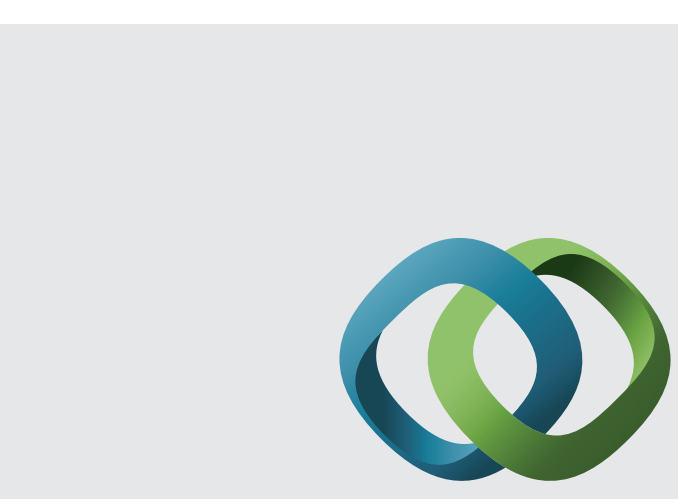

\section{Hindawi}

Submit your manuscripts at

http://www.hindawi.com
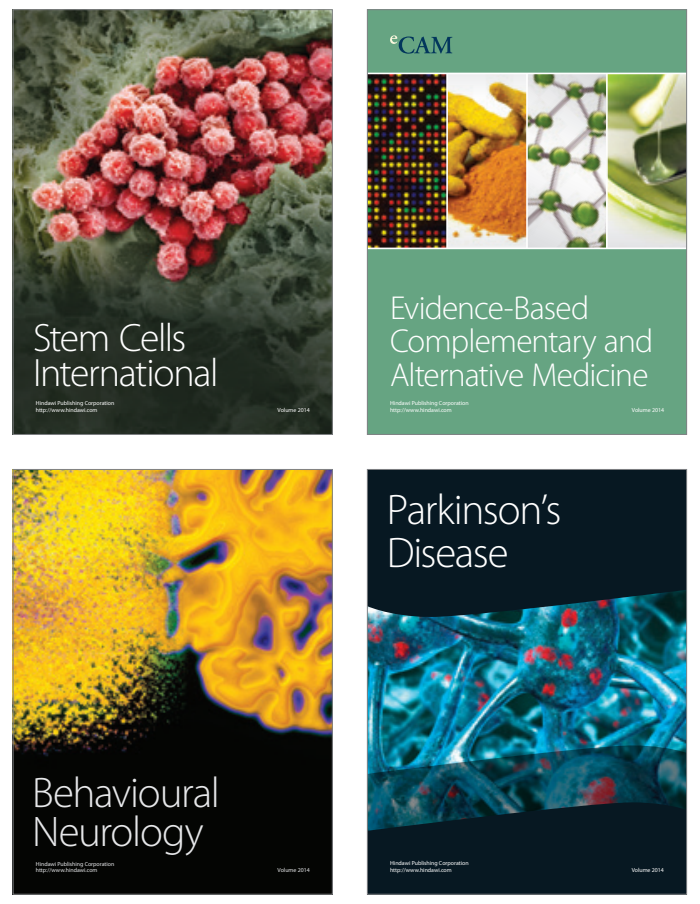
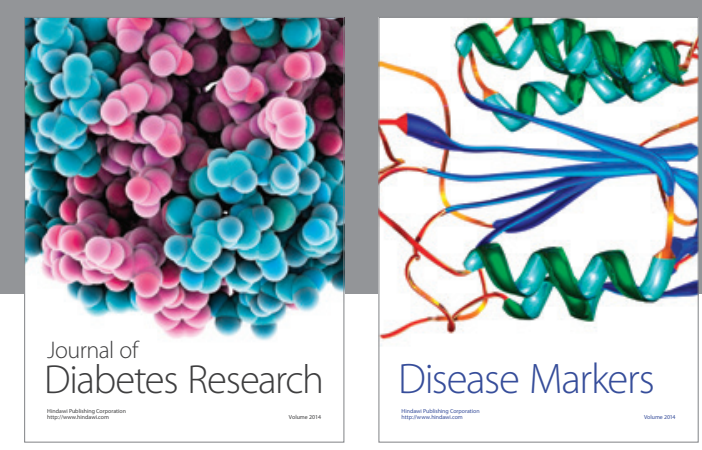

Disease Markers
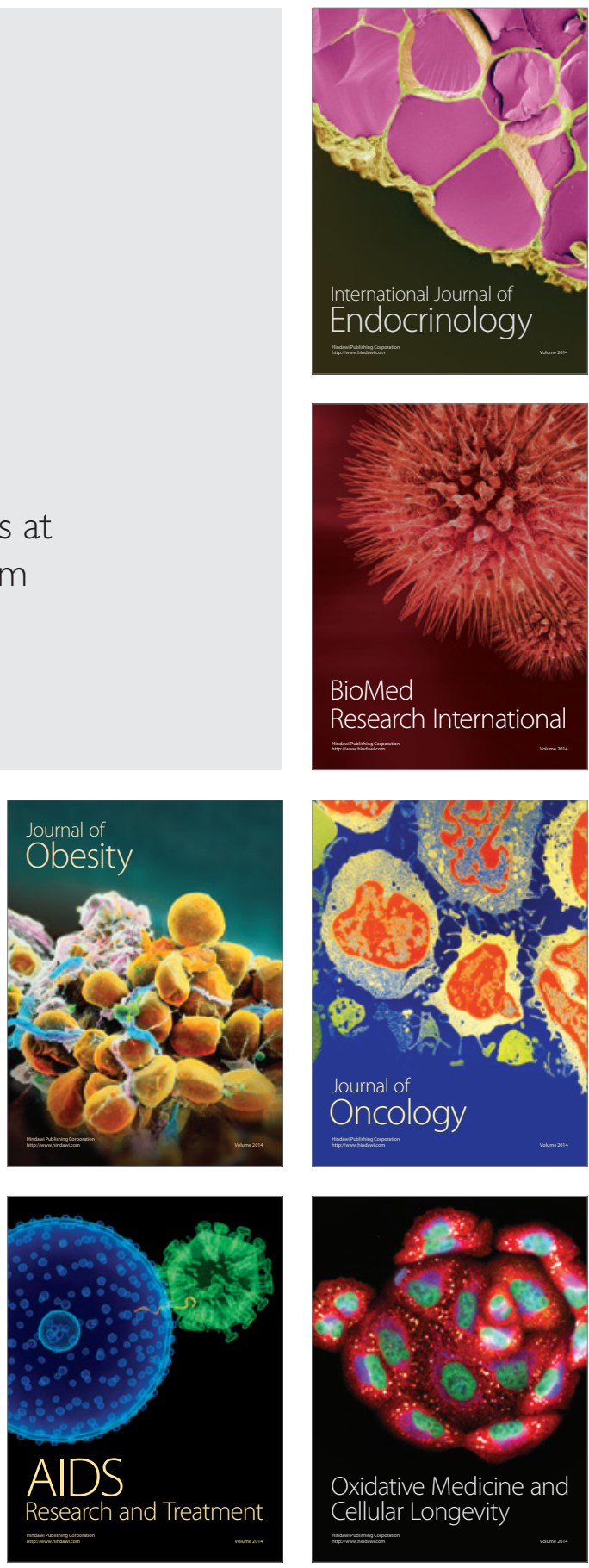